\title{
Reversible Hypoxia-Induced Thrombocytopenia in an Infant of Pulmonary Atresia with Ventricular Septal Defect
}

\section{Hanna Jung $(\mathbb{C}$ \\ Youngok Lee (D)}

Department of Thoracic and Cardiovascular Surgery, Kyungpook National University Hospital, Kyungpook National University School of Medicine, Daegu, Republic of Korea
This article was published in the following Dove Press journal: International Medical Case Reports Journal

\begin{abstract}
The presence of thrombocytopenia in cyanotic congenital heart disease (CCHD) is an uncommon, but well-known condition. We present a patient with pulmonary atresia with ventricular septal defect (PA with VSD) requiring a multi-stage operation. We were unsure whether the patient's hypoxia was the cause of his thrombocytopenia, as the hypoxia was relatively mild. His thrombocytopenia improved following reoxygenation after the Rastelli operation (total correction of PA with VSD). From these findings, we suggest that if a patient with CCHD presents with thrombocytopenia without an obvious cause, hypoxiainduced thrombocytopenia should be considered, regardless of the degree of hypoxia, platelet count, or hematocrit percentage.
\end{abstract}

Keywords: cardiac surgery, congenital heart defect, cyanosis, pulmonary atresia with ventricular septal defect, thrombocytopenia

\section{Introduction}

Thrombocytopenia is a deficiency of platelets in the blood, resulting in bruising, bleeding, and blood clots. It has various etiologies, and it is important to investigate the cause for each patient, so that the platelet count (PLT) can be increased. The relationship between thrombocytopenia and cyanotic congenital heart disease (CCHD) is well known, but the two conditions are rarely observed together. Surgery for a patient with thrombocytopenia increases the risk of bleeding. In addition, cardiac surgery using cardiopulmonary bypass aggravates bleeding due to platelet dysfunction and the consumption of coagulation factors. This further complicates the management of these patients, as the surgical complexity, the patient's condition, and the timing of the repair all have to be carefully considered. ${ }^{1}$ We present a case of a patient with pulmonary atresia with ventricular septal defect (PA with VSD) who required a multi-stage operation.

\section{Case Report}

A male newborn was referred to our hospital at 1 day of age. He exhibited cyanosis and his oxygen saturation $\left(\mathrm{SaO}_{2}\right)$ was at $80 \%$ (all $\mathrm{SaO}_{2}$ values below were measured in room air). In terms of laboratory findings (Figure 1), his hematocrit was $47.8 \%$, PLT was $103,000 / \mathrm{mm}^{2}$, and the other factors were in the normal range. The patient had moderate thrombocytopenia, but no signs or symptoms of infection. Echocardiography showed PA with VSD and patent ductus arteriosus (PDA).
Department of Thoracic and Cardiovascular Surgery, Kyungpook National University Hospital, Kyungpook National University School of Medicine, I 30 Dongdeok-ro, Jung-gu, Daegu 41944, Republic of Korea

Tel +82-53-200-5665

Fax +82-53-426-4765

Email yoleel210@knu.ac.kr 


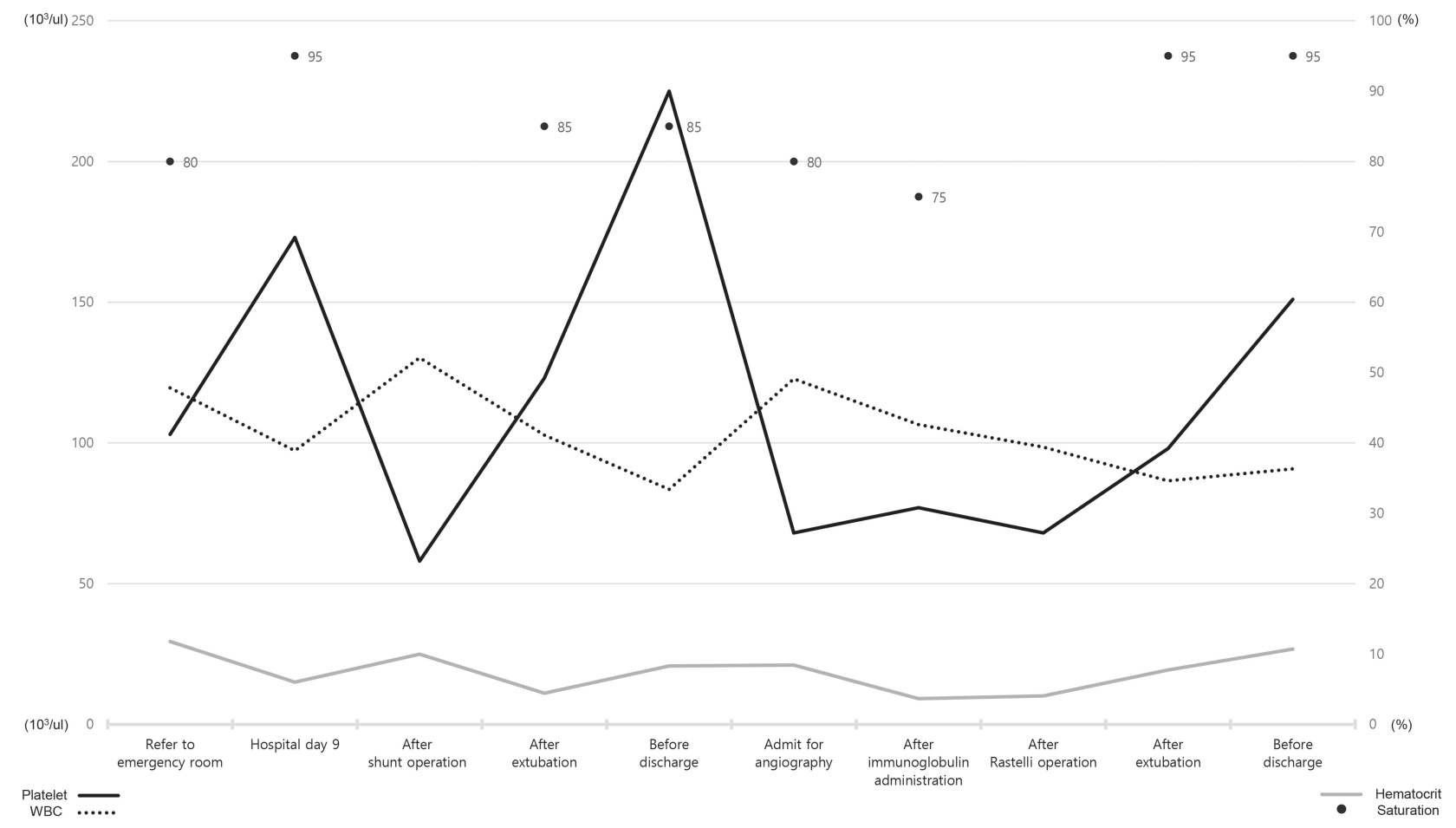

Figure I The patient's complete blood count (platelet, hematocrit, and WBC [white blood cell]) and oxygen saturation from the day after birth to the time of the Rastelli operation.

A prostaglandin infusion was started to maintain PDA patency and to support pulmonary circulation. $\mathrm{His} \mathrm{SaO}_{2}$ increased to 90 to $95 \%$. The attending pediatrician suspected neonatal alloimmune thrombocytopenia.

On day 11 after admission, the patient underwent a systemic to pulmonary shunt operation using an expanded polytetrafluoroethylene graft (W. L. Gore and Associates, USA), as well as PDA division. His preoperative hematocrit and PLT on day 10 post admission were $38.9 \%$ and $173,000 /$ $\mathrm{mm}^{2}$, respectively, and $\mathrm{SaO}_{2}$ was $95 \%$ with a prostaglandin infusion. His postoperative hematocrit and PLT were $52.1 \%$ and $58,000 / \mathrm{mm}^{2}$, respectively, under mechanical ventilation. The PLT increased over time without a transfusion. On postoperative day (POD) 6, the patient was extubated, and his $\mathrm{SaO}_{2}$ ranged from $80 \%$ to $85 \%$, his hematocrit was $41.1 \%$, and his PLT was $123,000 / \mathrm{mm}^{2}$. The patient was discharged on POD 13 when his $\mathrm{SaO}_{2}$ ranged from $85 \%$ to $87 \%$, his hematocrit was $33.4 \%$ and his PLT was $225,000 / \mathrm{mm}^{2}$. We were not concerned about the patient's previous thrombocytopenia, since his PLT had increased to the normal range.

Ten months later, he was admitted for a Rastelli operation, which is a total correction of PA with VSD. His $\mathrm{SaO}_{2}$ was $80 \%$ and the preoperative hematocrit and PLT were $49.1 \%$ and $68,000 / \mathrm{mm}^{2}$, respectively. The patient presented with thrombocytopenia again, but no history of bleeding or taking medications. His prothrombin time, activated partial thromboplastin time, and international normalized ratio were in the normal range, and a peripheral blood smear revealed no abnormalities. Antiplatelet antibodies and plateletassociated immunoglobulins were negative, and autoantibodies (anti-nuclear and anti-double-stranded deoxyribonucleic acid antibody) were normal. His platelet aggregation test result was $127 \mathrm{~s}$ (reference range, 61-110s), and viral and bacterial examination results were insignificant. The pediatrician made a provisional diagnosis of immune thrombocytopenia and recommended preoperative immunoglobulins $(2 \mathrm{~g} / \mathrm{kg} / \mathrm{day})$. Hypoxia-induced thrombocytopenia was a differential diagnosis, but this was difficult to conclude, as the patient's hypoxia did not drop his $\mathrm{SaO}_{2}$ to $60-70 \%$, and the duration of the hypoxia was less than 12 months, which is a relatively short time frame. Immunoglobulins were administered the day before the operation. On the day of the operation, his hematocrit was $42.6 \%$ and the PLT was $77,000 / \mathrm{mm}^{2}$, indicating that the immunoglobulins were ineffective. Hypoxia-induced thrombocytopenia was considered, which could only be diagnosed after the total correction of the hypoxia. We performed the Rastelli operation under platelet transfusion. The postoperative hematocrit was 
$39.4 \%$ and PLT was $68,000 / \mathrm{mm}^{2}$ under mechanical ventilation. The PLT increased over time without a transfusion. On POD 2, the patient was extubated, and his $\mathrm{SaO}_{2}$ was 90 to $95 \%$, the hematocrit $34.6 \%$ and the PLT was $98,000 / \mathrm{mm}^{2}$. He was discharged on POD 7, after his $\mathrm{SaO}_{2}$ was $95 \%$, the hematocrit was $36.3 \%$, and the PLT was $151,000 / \mathrm{mm}^{2}$.

Retrospectively reviewing the patient's $\mathrm{SaO}_{2}$ and laboratory findings, we assume that, although the patient had mild hypoxia and moderate thrombocytopenia for a relatively short duration, the patient may have had hypoxia-induced thrombocytopenia. There were no recurrences of thrombocytopenia at the one-year follow-up.

\section{Discussion}

Thrombocytopenia in CCHD generally occurs when the patient's hematocrit is greater than $65 \%$ and the arterial $\mathrm{SaO}_{2}$ is less than $65 \%$. $^{2}$ Reports of hypoxia-induced thrombocytopenia have occurred in cases of severe and chronic hypoxia. Multiple etiologies of the thrombocytopenia have been suggested, such as impaired platelets, megakaryocyte production, increased platelet destruction, and increased platelet activation. $^{2-6}$ However, the cause of thrombocytopenia has not been clearly identified and conflicting data still exists regarding its etiology. ${ }^{5,6}$ The PLT ranges widely based on the severity of the cyanosis and the amount of right-to-left shunt, which varies between patients. ${ }^{2-6}$

PA with VSD is categorized as a CCHD. However, our patient's $\mathrm{SaO}_{2}$ averaged $80 \%$, which is not considered severe cyanosis, and the duration of the hypoxia was less than 12 months. He had moderate thrombocytopenia, where the highest hematocrit was $49.1 \%$, and his lowest PLT was $68,000 / \mathrm{mm}^{2}$, which was not considered severely abnormal. The patient required a multi-stage operation with the use of a cardiopulmonary bypass, but the PLT may have dropped to critical levels, resulting in severe complications during surgery. Therefore, determining the cause of the thrombocytopenia and aggressively treating it before the cardiac surgery was important.

Eventually, our patient's thrombocytopenia improved following the reoxygenation after the total correction. The patient was diagnosed with hypoxia-induced thrombocytopenia. There are only a few case reports describing surgeries for CCHD with severe thrombocytopenia, such as with our patient. These reports describe reversible thrombocytopenia in a 3-year-old boy and an 8-year-old girl following reoxygenation after operations. 5,6 To the best of our knowledge, our report describes the first case to show reversible hypoxia-induced thrombocytopenia in an infant.

\section{Conclusion}

Based on our findings, if a patient with CCHD presents with thrombocytopenia without an obvious cause, hypoxia-induced thrombocytopenia should be considered, regardless of the degree and duration of the hypoxia, PLT, or hematocrit. Furthermore, in these cases, we may not need to be as concerned with postoperative bleeding because the thrombocytopenia will resolve itself after the corrective surgery. This may reduce the need for unnecessary preoperative management.

\section{Abbreviations}

CCHD, cyanotic congenital heart disease; PA with VSD, pulmonary atresia with ventricular septal defect; PLT, platelet count; $\mathrm{SaO}_{2}$, oxygen saturation; PDA, patent ductus arteriosus; POD, postoperative day.

\section{Ethics Approval and Informed Consent}

The study was approved by the Institutional Review Board of Kyungpook National University Hospital (IRB approval no. 2019-12-035). The patients' parents provided written informed consent for the publication of this case report.

\section{Disclosure}

The authors report no conflicts of interest in this work.

\section{References}

1. Al-Biltagi M, Ismail MF, Al-Radi OO, Baho H. A triple challenge: thrombocytopenia in a 7-year-old girl with unrepaired d-transposition of the great arteries, ventricular septal defect, and pulmonary hypertension. Pediatr Cardiol. 2013;34(8):2021-2023. doi:10.1007/ s00246-012-0570-7

2. Olgar S, Ertugrul T, Nisli K, Devecioglu O, Turkan E. Shunt operations improved thrombocytopenia in a patient with congenital cyanotic heart disease. Ann Thorac Cardiovasc Surg. 2008;14 (5):329-332.

3. Lill MC, Perloff JK, Child JS. Pathogenesis of thrombocytopenia in cyanotic congenital heart disease. Am J Cardiol. 2006;98(2):254-258. doi:10.1016/j.amjcard.2006.01.083

4. Horigome H, Hiramatsu Y, Shigeta O, Nagasawa T, Matsui A. Overproduction of platelet microparticles in cyanotic congenital heart disease with polycythemia. J Am Coll Cardiol. 2002;39 (6):1072-1077.

5. Matter RM, Ragab IA, Roushdy AM, Ahmed AG, Aly HH, Ismail EA. Determinants of platelet count in pediatric patients with congenital cyanotic heart disease: role of immature platelet fraction. Congenit Heart Dis. 2018;13(1):118-123. doi:10.1111/chd.12530

6. Patil S, Relan J, Hote M, Kothari SS. Severe thrombocytopenia in tetralogy of fallot patients: a contraindication for corrective surgery? Ann Pediatr Cardiol. 2019;12(3):305-307. doi:10.4103/ apc.APC_71_18 


\section{Publish your work in this journal}

The International Medical Case Reports Journal is an international, peer-reviewed open-access journal publishing original case reports from all medical specialties. Previously unpublished medical posters are also accepted relating to any area of clinical or preclinical science. Submissions should not normally exceed 2,000 words or 4 published pages including figures, diagrams and references. The manuscript management system is completely online and includes a very quick and fair peer-review system, which is all easy to use. Visit http://www.dovepress.com/testimonials.php to read real quotes from published authors. 